\title{
DIFFERENT APPROACHES TO TRAINING INTERPRETERS: HISTORICAL VIEW AND CONTEMPORARY IMPLEMENTATION
}

\author{
Nataliya Belenkova \\ Asst. Prof. Dr., Peoples' Friendship University of Russia, The Russian Federation, \\ belenkovanm@gmail.com
}

\begin{abstract}
Nowadays the international situation and wide political, social and cultural relations enhance the importance of interpreting from one language into another. The role of professionals in interpreting is also increasing. It causes the necessity of special training and development of interpreters at education institutions of different levels. Training interpreters can be realized from various didactic and methodological standpoints. To find the most effective way of training interpreters the previous practical experience of teaching and theoretical research in the field of interpreters' training methodology should be analyzed.

The topicality of the paper is explained not only by the increased interest in interpreting as a professional activity but also by a modern view on interpreting as a part of mediation that is considered by European researchers as a special language activity along with reading, speaking, writing and listening. As all language activities can be taught from the point of different lingo didactic approaches, consequently, training interpreting can also be studied as a realization of lingo didactic views and theories known in educational environment.

The purpose of this paper is to analyze different lingo didactic approaches to teaching foreign languages and their use in training interpreters practice; generalize the ideas of the previous studies and suggest the ways how to implement these theories into the modern practice of training interpreters-to-be more effectively; concentrate on the issues of training interpreters in a specific setting; present some examples from the practice of teaching and training interpreters at Peoples' Friendship University of Russia (RUDN University).
\end{abstract}

Keywords: linguo-didactics, methodology, interpreting, teaching and training interpreters-to-be, teaching approaches.

\section{INTRODUCTION}

Interpreting as a form and means of intercultural communication has been known for centuries. In trade and diplomatic relations, in wartime there were people who helped interlocutors speaking different languages to understand each other. The profession of an interpreter has always been of great demand. Interpreting training was realized in different ways. For many years, it was considered that the knowledge of two languages is enough to be an interpreter or that practising interpreting for hours is the best way to train interpreters (Fons, 2011).

Later it was recognized that interpreters-to-be should be aware of some theoretical research findings in different sciences including psychology, special discourse etc. Daniel Gile concentrated on the "Effort Model 
Theory" that studied interpreter's efforts in listening and analysis, memory, production, coordination. To succeed in interpreting activity it is important to balance all these efforts (Gile, 2009).

At the end of the XX century the European Union adopted "The Common European Framework of Reference for Languages: Learning, Teaching, Assessment" where interpreting as a part of mediation was examined as a language activity. It can be assumed that training interpreting can be implemented using lingo didactic approaches and technologies that are practised in developing foreign language skills in listening, speaking, reading and writing.

\section{METHODOLOGICAL THEORIES OF TEACHING FOREIGN LANGUAGES}

To study the most appropriate approaches to training interpreting the well-known theories in methodology of the foreign language teaching were analysed (Richards, Rodgers, 2014; Scrivener, 2011).

The first method that is worth being mentioned in the connection with the interpreters' training is Lexical Approach that concentrates on learning words, combinations and phrases as the main language units for learning. The ability to catch the meaning of a lexical cluster is very important for an interpreter. Moreover, very often the meaning of the word combination is not equivalent to the meaning of separate words of the combination. Therefore, an interpreter must know not only what separate words mean but also what concept the word cluster presents.

The ideas of Communicative Language Teaching or Communicative Approach in its soft version are used in training interpreting. Here a focus is made on listening and speaking activities, which help develop interpreting skills. The material and tasks for learning are taken from the situations of real life, genuine communication. Here we speak about the use of Task-Based Learning.

Tasks used in teaching English often take the form of role-playing, problem solving, cases, and simulated situations. The learners use different linguistic strategies, cognitive abilities, their previous linguistic experience and intention to fulfil the task. The learners are involved in verbal activity and so the Language Activity Development Approach is applied.

The principles of Cooperative Language Learning, that sometimes is called Collaborative Learning, are also used in training interpreting. According to this lingo didactic approach learning activity is organized in small groups or subgroups where students are involved in collaboration.

Nowadays Competence-Based teaching and learning of foreign languages is gaining popularity. The goal of training is the learners' output, i.e. what they can do with the language on the completion of the education period. As far as interpreting is concerned, the corresponding competencies are not well studied and described, though this approach should be used in teaching interpreters-to-be.

Content and Language Integrated Learning can be assumed as one of the key methods of teaching at a higher educational institution. This approach determines the subject matter of teaching and studying. It helps to simulate the situations where interpreting can be realized in the real communication of a particular setting.

Contemporary education cannot be imagined without the use of the information communication technologies that play a very important role in teaching. IC technologies are integrated into face-to-face teaching and learning and accompany the traditional way of teaching.

The nomenclature of the above mentioned lingo didactic approaches that can be used for training interpreter-to-be have not reached its limits. In our opinion other lingo didactic methodologies can be implemented into teaching practice, but the theories analyzed above have great influence on the development of interpreters in higher education institutions.

\section{PRACTICAL IMPLEMENTATION OF THE THEORETICAL IDEAS}

Any educational method is realized into teaching practice. Therefore, we can view the lingo didactic approaches from the position of their efficiency for training interpreting.

Traditionally interpreting skills are trained starting from the level of separate words. Usually these words are of one or two syllables and they are to be interpreted into another language in a short pause. Gradually the unit for interpreting increases to a word with more syllables, then two words, afterward to a word combination etc. At this level, grammar is not taken into consideration, grammar patterns are viewed as a lexical unit. At this level the speed of interpreting and its quality are of primary importance. If interpreters of a special setting 
are trained, they also memorize terms and concepts of the particular domain. In our opinion this practice is a bright illustration of the Lexical Approach.

When students' skills are developed enough to move to another stage they start to train interpreting sentences or short utterances. As a pre-interpreting activity students listen to a lot of information and news, watch video connected with the students' profession are discussed. Naturally, these issues cause much debates among the students and therefore listening and speaking skills are perfected. Then the same video recordings can be used for developing interpreting skills. First, students try to interpret the main characters of the video familiar to them. Interpreting the same piece of information can be repeated several times, thus the appropriate skills are enhanced. In our view, this is the realization of the Communicative Approach.

Then, students can try to interpret unfamiliar utterances and extracts of speech; in any case, the latter are connected with the students' field of study. Contemporary teaching practice cannot be imagined without creative activity of the learners. They are involved in simulating situations connected with their profession, e.g. court procedure with a participation of an interpreter, investigation of a crime etc.. Training interpreting can be based not only on the situations of the real life but also on the situations created by the students that is typical of Task-Based Learning.

As all assignments, problems or cases created and made by the students remind the real life communication, they develop the skills of all language activities, primarily listening and speaking. Very often interlocutors make notes while speaking and interpreting, so skills of writing and reading are trained as well. It is evident that the Language Activity Development Approach is realized.

Law Institute of Peoples' Friendship University of Russia runs an informal educational course of translation and interpreting in a law setting. The students enrolled in the course are trained in these two activities. At the beginning of the course students make translations of different materials connected with the subjects they learn. During classes they use their translations for training interpreting skills. The work is usually implemented in pairs where one student reads the initial statement another one interprets it into a target language. The first student can check whether the interpretation is right as he/she has a written translation of the extract. Then the following statement is read in a foreign language to be interpreted. Afterward the students are changing their roles and another learner is training the interpreting skills. Working in collaboration students increase their active participation in the learning process and enhance their motivation.

Apparently, the material used for interpreting practice should reflect the issues of the students' speciality (in our case it is law). It should be authentic, modern and contain topical information. In this way, the students not only develop interpreting skills but also learn much about different aspects of legislation, practical realization of court practice etc. If the learning process is organized in such a way learning a foreign language is integrated in studying the professional content.

Nowadays education cannot be imagined without the use of modern technologies especially information communication technologies. Training interpreting is connected with perceiving peoples' speech with different specific features inter alia not distinct pronunciation, national accent, mumbling. People can speak in the street or on the background of some noise. Therefore, students who are trained to be interpreters should know how to cope with all these problems and develop their interpreting skills in various environments. For this purpose, the videos from internet sites, e.g. "YouTube" or video lectures of the Faculty of Law, Cambridge University are widely used.

All language activities namely listening, speaking, reading and writing can be described in terms of a number of determinants typical of each level of language proficiency. Translation and interpreting are also considered as language activities but the appropriate determinants have not been worked out yet [Common, 2004]. So Competence based approach to training interpreters is a matter of further research and analysis.

\section{CONCLUSION}

Studying the development of linguo didactics it is evident that the issues of efficient teaching of foreign languages, on the one hand, and training different speech activities in a foreign language, on the other hand, are very topical. To achieve the objectives of education at different levels, the special higher education including, various pedagogical approaches should be applied in teaching practice. Having been developed in the last century these approaches are still relevant. They can and must be applied in the contemporary educational environment under new circumstances. Practical experience shows that though new ideas constantly appear, sometimes "it is not necessary to reinvent the wheel" and to get better results in teaching and training the achievements of earlier researches can be implemented. 


\section{REFERENCE LIST}

Common European Framework of Reference for Languages: Learning, teaching, assessment (2004) Cambridge, Cambridge University Press, $260 \mathrm{p}$

Fons M. (2011). Tag Archives: history of interpreting. https://theinterpreterdiaries.com/tag/history-ofinterpreting

Gile D. (2009). Basic Concepts and Models for Interpreter and Translator Training. Revised Edition. Amsterdam/Philadelphia: John Benjamins Publishing Company, pp. 278.

Richards J.C., Rodgers T.S. (2014). Approaches and Methods in Language Teaching. Cambridge University Press, pp. 409.

Scrivener J., (2011). Learning Teaching: The Essential Guide to English. 3rd edition. MacMillan, 416 p. 